\title{
Competition-induced starvation drives large-scale population cycles in Antarctic krill
}

\author{
Alexey B. Ryabov ${ }^{1 \star} \oplus^{\circ}$, André M. de Roos ${ }^{2} \odot$, Bettina Meyer ${ }^{1,3,4}$, So Kawaguchi ${ }^{5,6}$ and Bernd Blasius ${ }^{1,4}$
}

\begin{abstract}
Antarctic krill (Euphausia superba)-one of the most abundant animal species on Earth-exhibits a five to six year population cycle, with oscillations in biomass exceeding one order of magnitude. Previous studies have postulated that the krill cycle is induced by periodic climatological factors, but these postulated drivers neither show consistent agreement, nor are they supported by quantitative models. Here, using data analysis complemented with modelling of krill ontogeny and population dynamics, we identify intraspecific competition for food as the main driver of the krill cycle, while external climatological factors possibly modulate its phase and synchronization over large scales. Our model indicates that the cycle amplitude increases with reduction of krill loss rates. Thus, a decline of apex predators is likely to increase the oscillation amplitude, potentially destabilizing the marine food web, with drastic consequences for the entire Antarctic ecosystem.
\end{abstract}

A bundances of Antarctic krill can fluctuate interannually over an order of magnitude on both local ${ }^{1-4}$ and regional scales ${ }^{5,6}$, constituting one of the world's largest population cycles in absolute biomass. This cycle has important consequences for the entire Antarctic ecosystem, because krill occupies a key position in Southern Ocean food webs ${ }^{7,8}$, acting as a direct link between primary producers and apex predators.

A clear example of such oscillations is represented in the time series of summer krill abundance and length distributions collected over a period of 18 years ${ }^{4,9}$ on the Palmer long-term ecological research (Palmer LTER) grid in the Western Antarctic Peninsula (WAP) region (see Supplementary Materials, Methods). During this time, krill exhibited nearly four complete population cycles in length distribution, recruitment index, biomass and abundance with a period of five to six years (Fig. 1, left panel). An earlier monitoring program on Adélie penguin diet ${ }^{10}$, starting in 1987, shows evidence of five such cycles. Typically, cycles start with the spawning of new strong cohorts within two successive years ${ }^{11}$ (Fig. 1a), followed in the next years by peaks in the recruitment index (Fig. 1c), and an abrupt increase in krill biomass and abundance ${ }^{4}$ (Fig. 1e). Although decreasing in abundance, these cohorts dominate the population during the following three to four years, until new strong cohorts can prevail and the cycle repeats.

The mechanisms underlying this large-amplitude population cycle remain a topic of strong debate. A schematic representation of the krill life cycle (Supplementary Fig. 1b) shows that reproduction and maturation depend on the food level, which in turn is driven either directly by climate variability or indirectly (in a feedback loop) by consumption. The origin of the krill cycle has usually been attributed to the direct link caused by periodic climatological influences affecting krill fitness, such as the El Niño-Southern Oscillation index ${ }^{4}$, Southern Annular Mode $^{9}$, anomalies in primary production ${ }^{12}$, sea ice duration ${ }^{6,11}$ or sea surface temperature ${ }^{3}$.

\section{Results}

Climatological influences, however, do not explain the idiosyncratic pattern of the krill cycle: the occurrence of two successive strong year classes each followed by successful recruitment one year later; and the co-occurrence of the spawning of any new cohort with the extinction of the existing strong cohort. Nor can the climatic factors explain the observed negative effect of the total krill biomass, or of the biomass of reproductive females, on reproduction (Fig. 1g; Supplementary Fig. 1b). As shown in Fig. 1g inset, an increase in the total krill biomass above $3 \mathrm{mg}$ dry weight (DW) $\mathrm{m}^{-3}$ results in a small value (mean $=0.006$ individuals (ind.) $\mathrm{m}^{-3}$ ) of juveniles from a narrow range (s.d. $=0.009$ ind $\mathrm{m}^{-3}$ ) in the following summer. In contrast, when total krill biomass is small $\left(<3 \mathrm{mg} \mathrm{DW} \mathrm{m}^{-3}\right)$, juvenile abundance in the following summer is highly variable (mean $=0.1$ ind. $\mathrm{m}^{-3}$, s.d. $=0.098$ ind. $\mathrm{m}^{-3}$ ), which is a significant difference in the mean value ( $t$-test, $P=0.0038)$ and variance (F-test, $P<0.001)$. This suggests that recruitment is constrained by intraspecific competition when krill biomasses exceed a critical level, but depends on the environmental conditions when the krill biomass is small-an effect that stresses the influence of a feedback link of krill biomass on food level.

To evaluate to what extent intracohort and intercohort interactions contribute to the krill cycle, and how this biotic self-regulation works alongside bottom-up climate regulators, we propose and analyse a population dynamics model of Antarctic krill (Table 1; Supplementary Fig. 1a). We use a bioenergetic model to capture the effects of seasonality on reproduction and ontogenetic development of krill during its entire life cycle. The model relates the energetic demands of growth and fertility to the difference between ingestion and maintenance rates. Krill dominantly feed on pelagic phytoplankton and ice algae ${ }^{13}$, and our model assumes that all krill stages compete for a food resource (phytoplankton) during spring, summer and autumn, but that during winter (when primary productivity is limited by light), adult and one-year juveniles

${ }^{1}$ Institute for Chemistry and Biology of the Marine Environment, University of Oldenburg, 26111 Oldenburg, Germany. ${ }^{2}$ Institute for Biodiversity and Ecosystem Dynamics, University of Amsterdam, 1090 GE Amsterdam, the Netherlands. ${ }^{3}$ Alfred Wegener Institute for Polar and Marine Research, Scientific Division Polar Biological Oceanography, 27570 Bremerhaven, Germany. ${ }^{4}$ Helmholtz Institute for Functional Marine Biodiversity at the University of Oldenburg, 26129 Oldenburg, Germany. ${ }^{5}$ Australian Antarctic Division, Kingston, Tasmania, 7050, Australia. ${ }^{6}$ Antarctic Climate and Ecosystems Cooperative Research Centre, Hobart, Tasmania, 7000, Australia. *e-mail: alexey.ryabov@uni-oldenburg.de 

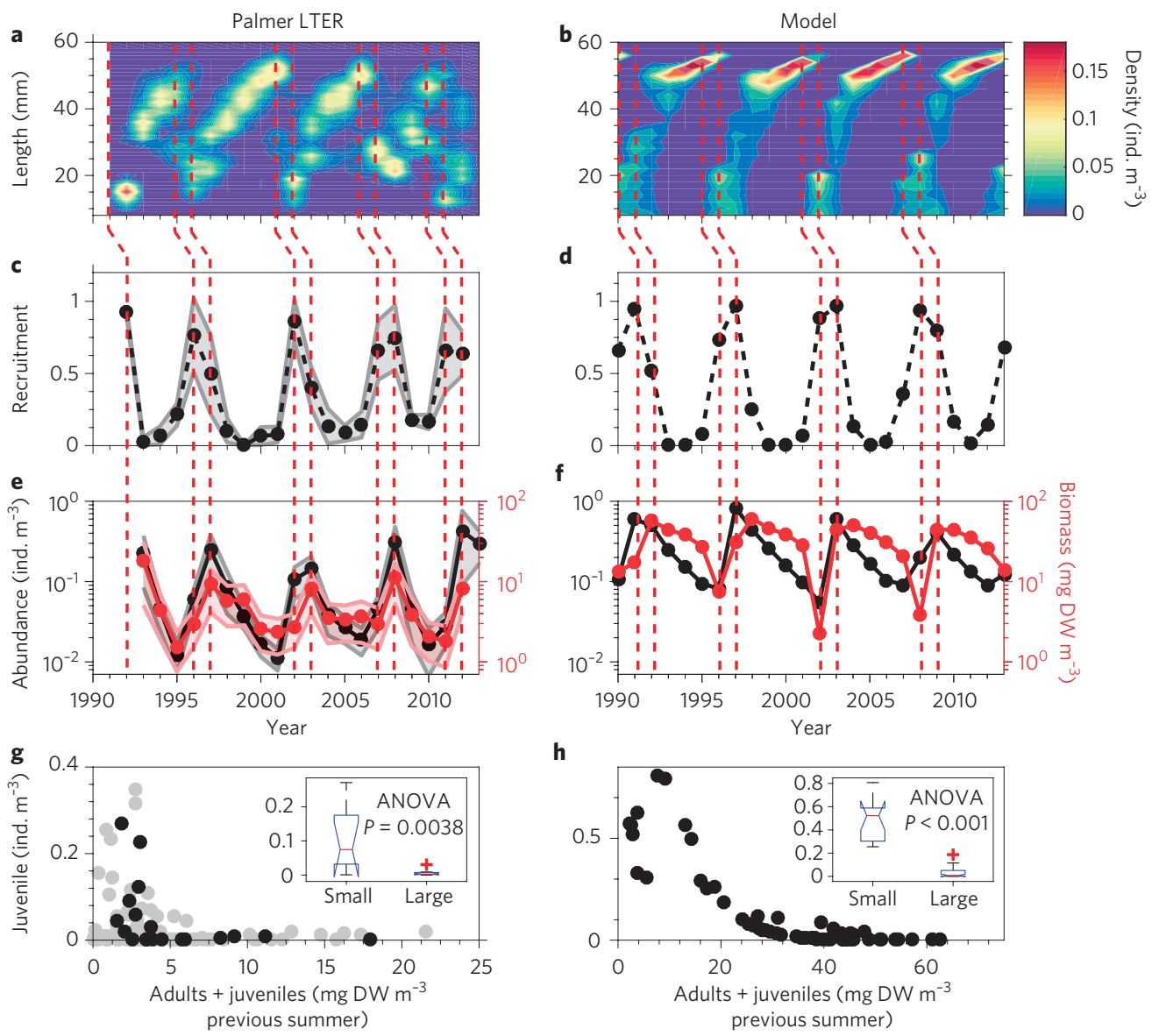

Figure 1 | Anatomy of the krill population cycle, Palmer LTER versus model. a,b, Krill length density distributions in colour coding, during summer. Vertical lines indicate spawning of strong krill cohorts ${ }^{4}$. c,d, Recruitment index; maxima occur one year after the successful spawning (grey shading shows \pm 1 s.d. across the Palmer LTER grid lines). e,f, Total abundance (black) and biomass (red) of juvenile and adult krill (shading shows \pm 1 s.d.). g,h, Negative effect of total krill biomass (adults + juveniles) on the abundance of juveniles in the following year, calculated in $\mathbf{g}$ for different lines of the Palmer LTER grid (grey) and for the whole grid (black). The insets show a box plot of the same data divided into two groups (small, large) with the total krill biomass either smaller or larger than $3 \mathrm{mg} \mathrm{DW} \mathrm{m}^{-3}$ in $\mathbf{g}$ and $20 \mathrm{mg} \mathrm{DW} \mathrm{m}^{-3} \mathrm{in} \mathbf{h}$. The simulations (right panel) assume a scenario without interannual variations in algal productivity. Field data are presented in Supplementary Table 5; see Methods for data analysis and model description.

overwinter in deep waters, while larvae are associated with sea ice and feed on the sea ice community ${ }^{14}$ (Table 1). We also assume that the starvation risk is significant for larval krill due to their low body lipid levels ${ }^{15,16}$, while adults and juveniles can accumulate large lipid reserves to survive longer periods of starvation ${ }^{17}$. Environmental variability is implemented as stochastic interannual changes of phytoplankton carrying capacity. A detailed model description and parameters are provided in Supplementary Information and Supplementary Tables 1-4.

Parametrized for WAP conditions, our model provides results that are in excellent agreement with observations (Fig. 1, right panel). The model predicts population cycles with periods of about five to six years that occur even in the absence of interannual variability in plankton productivity. These cycles are related to cyclic increases in starvation mortality of larval krill (Fig. 2a) and are induced by the interplay between the seasonality of the Antarctic environment with the ontogenetic structure of krill populations (Fig. 2c,d). The seasonal succession of phytoplankton and ice algae-the two main food resources-leads to seasonal variations in the grazing impact of krill on phytoplankton, with two local maxima (up to $70 \%$ of primary production ${ }^{18}$ ) during spring and autumn, when the ingestion rates of krill are high but primary production is small. This periodic depletion of resources gives rise to cyclic peaks in starvation mortality among larvae and juveniles. While during spring, larvae can still profit from sea ice, during autumn there is typically a time gap between the formation of ice algae after the breakdown of phytoplankton, making autumn a potential bottleneck for krill survival. Thus, although krill affect phytoplankton concentrations during

Table 1 | Main stages of krill development (see Methods for the model description).

\begin{tabular}{lllll} 
Stage & Embryos & Larvae & Juveniles & Adults \\
\hline Age & $0-30$ days & $30-365$ days & $>1$ year & $>2$ years \\
Consumption & No & Ice algae or phytoplankton & Phytoplankton & Phytoplankton \\
Starvation mortality & No & Yes & Yes, if size $<10 \mathrm{~mm}$ & No \\
Reproduction & & & If size $>35 \mathrm{~mm}$
\end{tabular}



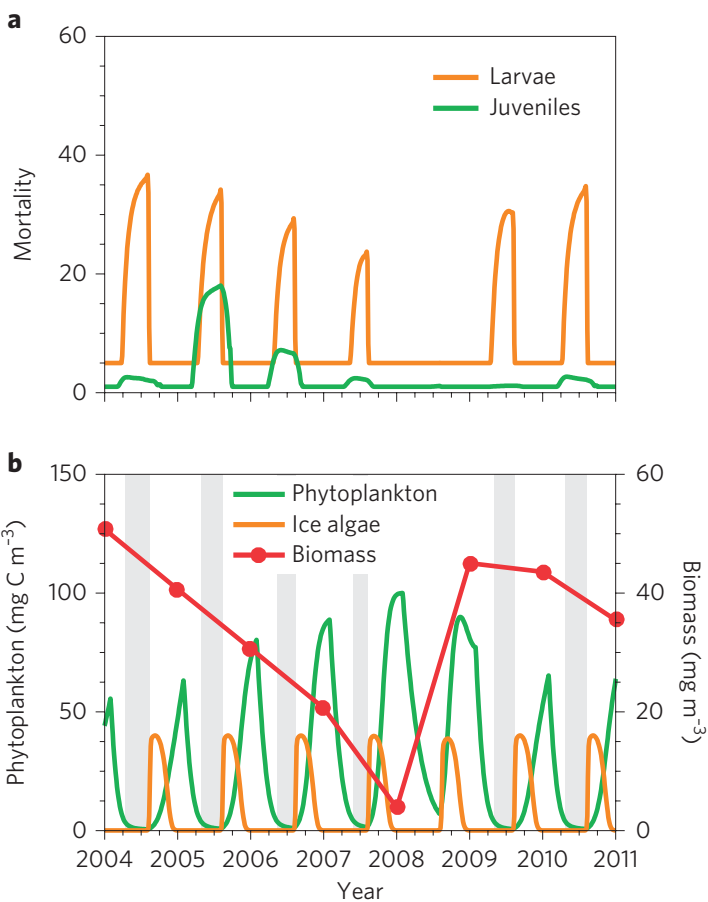

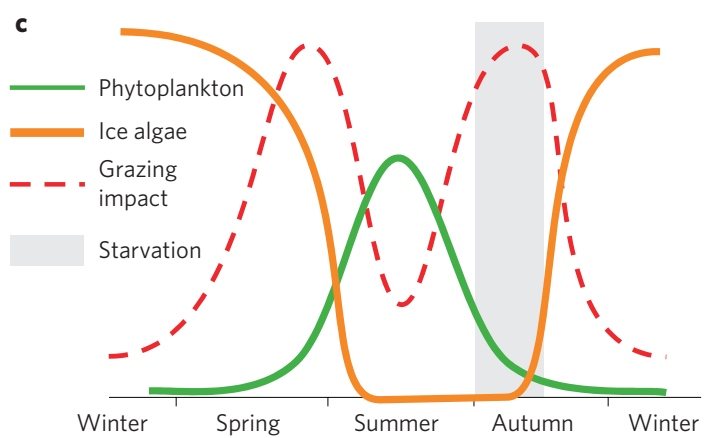

d

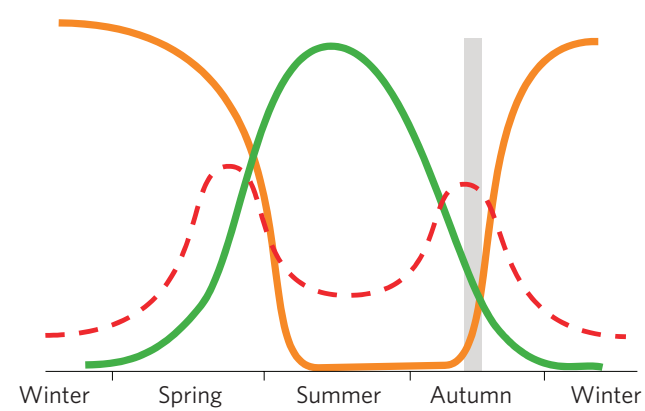

Figure $\mathbf{2}$ | Mechanism of the multi-annual cycles in krill biomass. a,b, Temporal changes over one period of the cycle, showing the simulated time course of starvation mortality among larvae (orange) and juveniles (green) (a), and total krill biomass (red) and its food resources: phytoplankton (green) and ice algae (orange) (b). c,d, Schematic representation of the annual dynamics for large (c) and small (d) krill biomass, showing phytoplankton (green), ice algae (orange) and krill grazing impact (percentage of primary production grazed by krill) on phytoplankton (red dashed line). The grey bars indicate starvation periods. When the total krill biomass is large, autumn becomes the main bottleneck for population survival.

the whole year, the top-down control during autumn is the crucial mechanism of the density-dependent regulation of reproduction.

Consequently, autumn phytoplankton concentrations, and hence the duration and intensity of the starvation periods, are strongly sensitive to krill biomass density. An abundant krill population accelerates the decline of the phytoplankton concentration in autumn and depletes phytoplankton to extremely low concentrations early, leading to a long starvation period (Fig. 2c). In contrast, a low krill population has a smaller impact on phytoplankton density, leading to reduced starvation mortality (Fig. $2 \mathrm{~d}$ ), therefore autumn phytoplankton concentrations are sufficient for larvae to survive and to reach an advanced stage before winter. After the first recruitment at the onset of a cycle, the population consists mainly of juveniles, which have limited impact on food levels, and a second larvae cohort can survive. However, with further increase of krill biomass, phytoplankton concentrations are reduced to a critical level, which elevates larval starvation mortality and results in recruitment limitation in the following year. A new cohort of larvae thus survives only when the biomass of the dominating cohorts has fallen below a critical level-giving rise to oscillations in biomass with periods corresponding to the lifetime of the dominating krill cohort (Fig. 2b).

This mechanism naturally explains the above described patterns of the krill cycle: two successive years of successful recruitment followed by three to four years of reduced recruitment (Fig. 1d); the appearance of a new strong cohort related to the extinction of an old one (Fig. 1b); and the negative effect of high post-juvenile krill biomass on the juvenile abundance one year later (Fig. 1h). The mechanism generating population cycles by food limitation is robust to different forms of grazing, including a scenario when the habitats of adults and juveniles decouple so that phytoplankton is grazed only by larvae (Supplementary Fig. 3). In this case, a large cohort of adults affects the phytoplankton concentrations indirectly: they produce numerous larvae (up to $30 \%$ of the biomass), which have a strong grazing impact on the phytoplankton at the onset of autumn, causing their starvation later.

It is often argued that the peaks in recruitment index correlate with elevated phytoplankton levels during the preceding summer ${ }^{9,12}$. We observe the same effect in the krill model (Supplementary Fig. 4b); however, here correlation does not imply causation: in the model, variations in phytoplankton concentrations are modulated by changes in population grazing rates during the population cycle, and not vice versa. A more detailed analysis shows that embryos and larvae reach high abundances in the years with low summer phytoplankton concentrations, because these periods match the maxima of the adult population. These cohorts, however, become extinct because survival during autumn, rather than fertility during summer, determines recruitment success (Supplementary Fig. 5).

Our model framework allows addressing of the interplay between exogenous and endogenous factors in shaping the krill population cycle (Supplementary Fig. 1b). Model simulations incorporating among-year variations in algal productivity show that the characteristic population cycles are retained under different external disturbance modes, although the cycle dynamics can be strongly affected (Supplementary Fig. 4, left panel). The correlation between summer phytoplankton concentrations and krill abundance in the following year at first slightly decreases with increasing interannual variability, but starts to increase monotonically for larger disturbance levels (Supplementary Fig. 4, middle panel). The lack of food can lead to low recruitment even when the total krill biomass is small (Supplementary Fig. 4, right panel). However, irrespective of the summer conditions, the maximal abundance of juveniles always decreases with the total krill biomass in the previous year-clearly indicating the limitation of krill survival by resource competition.

Even though interannual environmental variability may not be the main driver of local cycles in krill abundance, it could well 

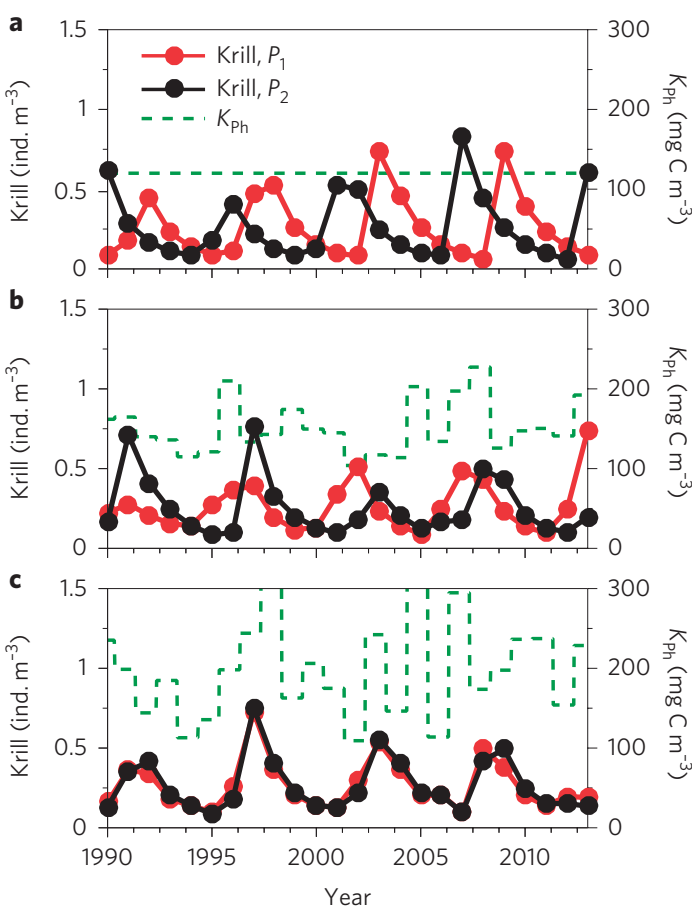
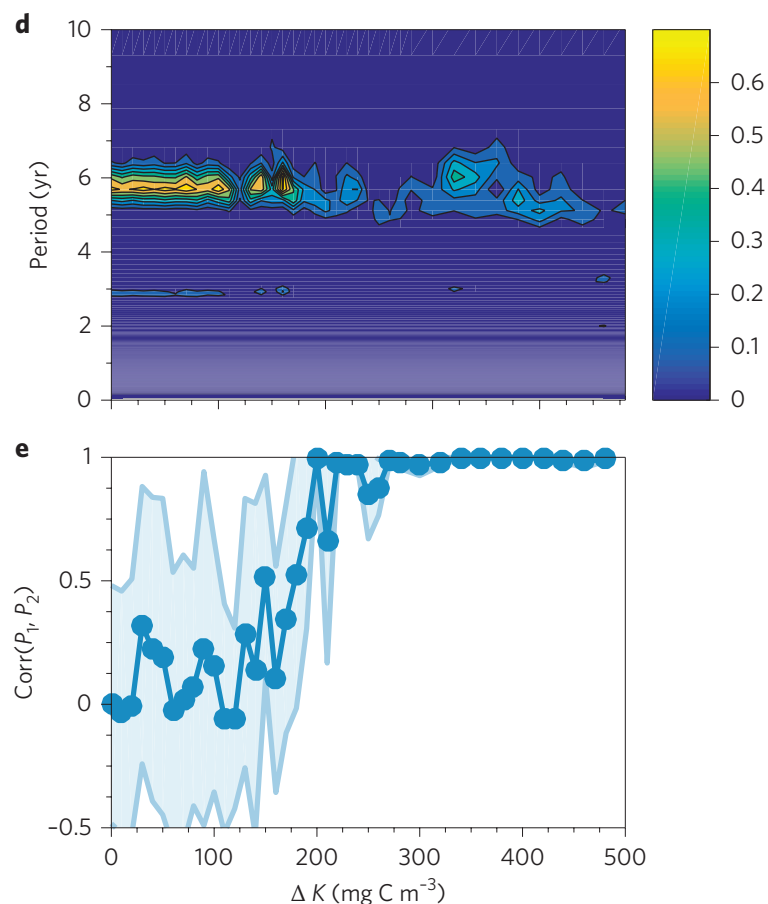

Figure 3 | Effect of interannual variations in algal productivity on krill population dynamics and synchrony. a-c, Simulated dynamics of two krill populations, $P_{1}$ (red) and $P_{2}$ (black), subjected to identical environmental perturbations (levels of $K_{\text {ph }}$ are shown by green dotted lines). All plots compare simulations, starting from different initial conditions, after a transient of 80 simulation years. $\mathbf{a}$, In the absence of external perturbations, $\Delta K=0$, the populations remain out of phase. $\mathbf{b}, \mathbf{c}$, With larger environmental variability, $\Delta K=120 \mathrm{mg} \mathrm{C} \mathrm{m}^{-3}$ (b) and $\Delta K=210 \mathrm{mg} \mathrm{C} \mathrm{m}^{-3}$ (c), the population cycles are increasingly synchronized, even though they started with different initial conditions (Moran effect). d,e, Response to different levels of external disturbances, indicated by the value of $\Delta K$. The power spectrum of a single population (colour coding) shows a maximum at a period of around six years for the whole range of noise levels $(\mathbf{d})$. The average correlation coefficient, $\operatorname{Corr}\left(P_{1}, P_{2}\right)$, between the two krill populations $( \pm 1$ s.d. shown in blue shading) increases with the level of external disturbances and reaches complete synchronization at $\Delta K>200 \mathrm{mg} \mathrm{C} \mathrm{m}^{-3}$ (e). See Methods for model parameters.

be a decisive factor for synchronizing them across a larger scale. If the oscillations were induced only by the population dynamics, we would expect them to be out of phase in different parts of the region. In contrast, field data indicate that the oscillations are synchronized across the entire Palmer LTER sampling grid, over more than $500 \mathrm{~km}$ from north to south ${ }^{4}$. One possible explanation is that populations in different regions are synchronized by random climatological factors (Moran effect) ${ }^{19,20}$. This hypothesis is confirmed by numerical simulation of krill populations subjected to interannual variability in algal productivity: the correlation between two separate populations, starting at different initial conditions, increases with the level of environmental disturbances, leading ultimately to a complete synchronization of two uncoupled populations (Fig. 3).

\section{Discussion}

Our results demonstrate that the five to six year cycle between high and low krill abundance is a self-sustaining mechanism, driven by intraspecific food competition, whereas the climatology is a superimposed factor that can modulate its phase and synchronization over large scales. The suggested model was parametrized for the WAP region, but can be used as a powerful tool to test possible hypotheses on krill life history in other regions of the Southern Ocean. According to our model, the stability of the krill cycle depends crucially on the delicate balance between krill reproduction and consumption, which is strongly influenced by ongoing changes in the Antarctic environment. In particular, any factor that increases future krill loss rates is likely to dampen the krill cycle (Supplementary Fig. 6). Thus, an increased predation pressure, caused for instance by recovering whale populations, paradoxically might stabilize krill populations. This effect can be further enhanced by the krill consumption by Baleen whales, which releases Fe locked up in the krill body. This released Fe could be a stimulant for phytoplankton growth ${ }^{21}$, thus potentially reducing the autumn bottleneck and further suppressing the krill cycle. On the other hand, future krill loss rates might well be reduced by a variety of factors, such as the anticipated decrease in other apex krill predators (for example, seals, penguins, albatross) ${ }^{10,22,23}$, changes in harvesting of krill, or the separation between krill and predator habitats caused by climate change ${ }^{4}$. Such reductions in krill loss rates might, in turn, amplify the amplitude of the oscillations in the biomasses of krill and their predators, with the potential to destabilize the Antarctic marine food web ${ }^{24,25}$ and ecosystem. Possible consequences include increased likelihood of algal blooms, reproductive failure of krill consumers and opening up of a niche for krill competitors such as salps ${ }^{6}$.

\section{Methods}

Data. The Palmer LTER program studies the WAP region ${ }^{4,12}$. A grid of Palmer LTER sampling stations extends from Anvers Island $\left(64.77^{\circ} \mathrm{S}, 64.05^{\circ} \mathrm{W}\right)$ in the north to approximately $700 \mathrm{~km}$ south near Charcot Island $\left(69.45^{\circ} \mathrm{S}, 75.15^{\circ} \mathrm{W}\right)$, and from coastal waters to more than $200 \mathrm{~km}$ offshore. Grid lines perpendicular to the peninsula are spaced $100 \mathrm{~km}$ apart with coordinates in kilometres from Marguerite Bay (000) to Anvers Inland (600). The stations along each line are spaced $20 \mathrm{~km}$ apart with coordinates also in kilometres from the continent (000) to offshore (200 and farther; see Supplementary Figs 10-12 for the maps and a detailed description of the sampling methods in ref. ${ }^{12}$ ). Only lines $200,300,400,500$ and 600 , and standard stations with numbers $-80,-60, \ldots 260$ (as annotated in the data file) were included in our study, as for these locations the data were available for the whole period of observations. Thus, the presented data are averaged over a grid that extends for $400 \mathrm{~km}$ from south to north along the Atlantic Peninsula and for more than $200 \mathrm{~km}$ from west to east. We analyse data obtained from a series of 22 cruises: one in spring (November 1991) and 21 in summer (1 January 10 February) for krill size distributions (from 1993 to 2012) and for krill 
abundances (from 1993 to 2013). The sampling frequency across the grid changed with time: in 1991, only nine stations were sampled; in the period from 1993 to 2008 , the sampling intensity was the highest and 36 to 55 stations were sampled each year; and in the last five years from 2009 to 2013, the sampling intensity was strongly decreased and only 13 to 17 stations were sampled per year. Following ref. ${ }^{4}$, we removed the outliers with extremely high krill densities (one measurement in 1993 and in 2002, and two measurements in 1998).

Average abundance and size distribution. The average abundance and variance was estimated as the mean across all grid stations based on the delta distribution $^{26}$, as this approach provides a more efficient estimator for the mean abundance when sampling data contain a large proportion of zeros, as typically happens for swarming animals such as krill. The implementation of this method in the deltadist function of the fishmethods package in $\mathrm{R}$ was used, but ported into MATLAB. Krill size distribution was calculated with $1 \mathrm{~mm}$ bin size and we used the delta distribution mean to find the average size distribution across the whole grid.

Recruitment index. (Fig. 1c,d) Defined, for the field data, as the fraction of individuals in the population smaller than $30 \mathrm{~mm}$ and, for the model, as the fraction of one-year-old individuals among all juvenile and adult krill. The total dry biomass was calculated as the product of krill abundance and krill average weight $\langle w\rangle=\int w(L) f(L, t) d L$, where $w(L)=c_{w} L^{\sigma_{1}+\sigma_{2} \ln L}$ is the relationship between length $L$ and dry weight (see below), and $f(L, t)$ is the normalized krill length distribution at time $t$.

Environmental interannual disturbances. (Fig. 3; Supplementary Fig. 4) Simulated as random interannual changes in phytoplankton carrying capacity $K_{\mathrm{Ph}}$. The values $K_{\mathrm{Ph}}$ were uniformly distributed in the range $\left[K_{\mathrm{Ph}, \text { min }}, K_{\mathrm{Ph}, \max }\right]$, where $K_{\mathrm{Ph}, \text { min }}=120 \mathrm{mg} \mathrm{C} \mathrm{m}^{-3}-0.24 \Delta K, K_{\mathrm{ph}, \max }=120 \mathrm{mg} \mathrm{C} \mathrm{m}^{-3}+\Delta K$ and $\Delta K=0 \ldots 480 \mathrm{mg} \mathrm{C} \mathrm{m}^{-3}$ sets the level of interannual variability in phytoplankton production. Figure 3a-c shows results for $K_{\mathrm{ph}}=120 \mathrm{mg} \mathrm{C} \mathrm{m}^{-3}$ and $K_{\mathrm{ph}}$ between $91 \ldots 240 \mathrm{mg} \mathrm{C} \mathrm{m}^{-3}$ and $70 \ldots 330 \mathrm{mg} \mathrm{C} \mathrm{m}^{-3}$, respectively (corresponding to $\Delta K=0$, 120 and $210 \mathrm{mg} \mathrm{C} \mathrm{m}^{-3}$ ).

In all simulations, the populations started with different initial conditions. Thereby, the initial phase difference between population $P_{1}$ and $P_{2}$ was set to three years (so that the two populations started approximately in antiphase). Figure 3 shows simulation runs after a transient of 80 years; that is, only the last 20 years of the total simulation of 100 years are shown.

To calculate the correlation coefficients (Fig. 3e), we first modelled each population independently for a randomly chosen period of time from 0 to 12 years. Then the final state was used as a new initial condition and both populations were subjected to the same environmental signal, $K_{\mathrm{ph}}(t)$, during 100 years. The correlation coefficient was found for the last 20 years of the simulation time and averaged over 60 pairs of populations with random initial phase shifts. Supplementary Fig. 4 (top three rows) shows results for $K_{\mathrm{Ph}}=120 \mathrm{mgC} \mathrm{m}^{-3}$ and $K_{\mathrm{Ph}}$ between $77 \ldots 350 \mathrm{mg} \mathrm{C} \mathrm{m}^{-3}$ and $30 \ldots 600 \mathrm{mg} \mathrm{C} \mathrm{m}^{-3}$, respectively $\left(\Delta K=0,230\right.$ and $\left.480 \mathrm{mg} \mathrm{C} \mathrm{m}^{-3}\right)$. In Supplementary Fig. 4 bottom row, we assume that phytoplankton carrying capacity, $K_{\mathrm{Ph}}$, is driven by the Southern Annular Oscillations index 9 , namely, $K_{\mathrm{Ph}}=K_{\mathrm{Ph}, 0} \exp (-0.3 \mathrm{SAM})$.

Ontogenetic model of krill population dynamics. (Supplementary Fig. 1). We model continuous growth and development of krill cohorts during their life cycle. We assume that growth, maturity and fecundity of individuals in each cohort depend on the food level and on their size and stage, where the food level is a balance between primary production, losses and consumption. Although krill are omnivorous, they feed primarily on phytoplankton and ice alga $e^{27}$. We assume that algal productivity is seasonally driven with a maximum of phytoplankton during summer and a maximum of ice algae during winter (Supplementary Fig. 7).

Krill development includes four functionally different stages: embryos, larvae, juveniles and adults (Table 1). During the embryonal stage, krill do not eat and develop using yolk reserves. This stage lasts approximately 30 days ${ }^{15}$. The second stage (larvae) lasts approximately one year. In most simulations, we assume that larvae compete with other krill stages for phytoplankton during summer (see, however, Supplementary Fig. 3), but only larvae can feed on ice algae during winter, when adults are inactive ${ }^{14}$. Larvae have high metabolic rates and cannot survive a long period of starvation ${ }^{15,16}$. After the first winter, krill reach the juvenile stage. Juveniles feed on phytoplankton during summer and increase in size. The starvation mortality decreases with size and approaches zero for 20-mm-long krill. These individuals can compensate for maintenance during starvation by losing their weight ${ }^{17}$. Background mortality (including predation and fishing) decreases with size but rises on reaching the individual age of around six years ${ }^{28}$. Krill metabolic rates depend on temperature; we model this dependence implicitly assuming that the metabolic rate follows a periodic function, and during winter juveniles and adults reduce their metabolic activity to $20 \%$ of the summer level ${ }^{29}$ (Supplementary Fig. 7a). After the second winter, krill enters the adult stage. Adult krill can reproduce if resources are high enough and they have reached the reproductive body size. To model krill development, we use a net production type energy budget approach, which links the growth and fecundity rates to the difference between ingestion and maintenance rates.

Let $w$ denote the dry weight of individuals, $a$ their age and $P$ the resource availability. Then the evolution of the age-weight distribution $c(t, a, w)$ of krill can be described in terms of a partial differential equation ${ }^{30}$ :

$$
\begin{aligned}
& \frac{\partial c(t, a, w)}{\partial t}+\text { growth }+ \text { ageing }=- \text { death } \\
& \frac{\partial c(t, a, w)}{\partial t}+\frac{\partial g(P, w) c(t, a, w)}{\partial w}+\frac{\partial c(t, a, w)}{\partial a}=-d(P, a, w) c(t, a, w)
\end{aligned}
$$

where $g(P, w)$ is the daily growth rate in weight and $d(P, a, w)$ is the death rate, which includes predation and starvation mortality.

As the number of new individuals (of weight $w_{\text {egg }}$ and age 0 ) equals the amount of eggs produced per unit of time by females above the reproductive weight $w_{\text {repr }}$ and age $a_{\text {repr }}$ we obtain the left boundary condition:

$$
c\left(t, 0, w_{\text {egg }}\right)=\frac{1}{2} S \int_{a_{\text {repr }}}^{a_{\max }} \int_{w_{\text {repr }}}^{w_{\max }} \mu(P, a, w) c(t, a, w) \mathrm{d} w \mathrm{~d} a
$$

where $\mu(P, a, w)$ is the female fecundity, $S$ is the egg hatchability and the factor $1 / 2$ in front of the integral appears because females constitute approximately one-half of the entire population.

The growth of individuals is coupled with the resource dynamics. Denote $P_{\mathrm{Ph}}$ the density of phytoplankton in the water column and $P_{\text {Ice }}$ the density of ice algae. Then the resource dynamics follow the equations:

$$
\begin{aligned}
\frac{\mathrm{d} P}{\mathrm{~d} t} & =\text { growth }- \text { ingestion }- \text { loss }+ \text { inflow } \\
\frac{\mathrm{d} P_{\mathrm{Ph}}}{\mathrm{d} t} & =g_{\mathrm{Ph}}(t) P_{\mathrm{Ph}}\left(1-\frac{P_{\mathrm{Ph}}}{K_{\mathrm{Ph}}}\right)-\int_{\text {All stages }} I\left(P_{\mathrm{Ph}}, w\right) c(t, a, w) d w-l P_{\mathrm{Ph}}+\delta_{\mathrm{Ph}, \text { in }} \\
\frac{\mathrm{d} P_{\text {Ice }}}{\mathrm{d} t} & =g_{\text {Ice }}(t) P_{\text {Ice }}\left(1-\frac{P_{\text {Ice }}}{K_{\text {Ice }}}\right)-\int_{\text {Larvae }} \rho I_{\text {Ice }}\left(P_{\text {Ice }}, w\right) c(t, a, w) d w-l P_{\text {Ice }}+\delta_{\text {Ice, in }}
\end{aligned}
$$

Here, the periodic functions $g_{\mathrm{ph}}(t)$ and $g_{\mathrm{ice}}(t)$ modulate the seasonal growth of phytoplankton and ice algae; $K_{\mathrm{Ph}}$ and $K_{\mathrm{Ice}}$ are the corresponding carrying capacity for each resource; $I\left(P_{\mathrm{Ph}}, w\right)$ and $I_{\mathrm{Ice}}\left(P_{\mathrm{Ice}}, w\right)$ are the ingestion rates; $\rho$ is a concentration factor relating the krill densities, when feeding on ice algae in a small volume below the ice, to their density within the water column; $l$ is the loss rate of the resource via sinking and grazing by other zooplankton species; and $\delta_{\mathrm{Ph}, \text { in }}$ and $\delta_{\mathrm{Ice}, \text { in }}$ denote the input from external sources, such as adjacent patches. To simulate environmental disturbances, we assume that different summers are characterized by random values of $K_{\mathrm{Ph}}$.

The model was parametrized using the latest available data (Supplementary Tables 1-4) and simulated with a numerical method for the integration of physiologically structured models ${ }^{31}$

Relationship between krill length and dry mass. During the embryonal and the following non-feeding stages, krill individuals increase their length, $L$, but the weight stays approximately unchanged, $w_{\text {egg. }}$. At later stages, typically $w \sim L^{\sigma}$, with an exponent $\sigma$ that increases with krill size (Supplementary Fig. 8a) ${ }^{32-35}$. To match the relationship throughout the entire range, we assume a quadratic relation between the logarithm of weight and logarithm of length, $\ln w=a+b \ln L+c \ln ^{2} L$, which can also be written as

$$
w=c_{w} L^{\sigma_{1}+\sigma_{2}} \ln L
$$

The inverse relation expresses the krill length as a function of krill weight:

$$
L(w)=\exp \left[\frac{-\sigma_{1}+\sqrt{\sigma_{1}^{2}+4 \sigma_{2} \ln \left(w / c_{w}\right)}}{2 \sigma_{2}}\right]
$$

We use equation (2) to compare the modelled krill traits, expressed as a function of krill weight, with field measurements typically expressed as a function of krill length.

Growth rate and fecundity. Defined in terms of a bioenergetics approach. We assume that assimilated food, after covering maintenance requirements, is invested into either body growth or reproduction. Namely, a fraction $K(w)$ of the difference between assimilated carbon and maintenance costs is invested into growth, and the rest $(1-K(w))$ into maturation or reproduction processes, where $K(w)$ is a decreasing function of krill size (Supplementary Fig. 8b). During starvation, krill does not invest into maturation, and the maintenance is covered at the expense of body reserves. 
To formulate the bioenergetics model, we express the net production rate $A(P, w)$ as the difference between the assimilation rate and maintenance costs:

$$
A(P, w)=[\varepsilon I(P, w)-T(w)] w
$$

where $I(P, w)$ is the weight specific ingestion rate, $\varepsilon$ the conversion coefficient from the assimilated ingested carbon into the dry body weight equivalents and $T(w)$ the weight specific maintenance rate.

Then the daily growth rate in weight equals

$$
g(P, w)=\frac{\mathrm{d} w}{\mathrm{~d} t}=\left\{\begin{array}{cc}
K(w) A(P, w) & \text { if } A(P, w) \geq 0 \\
A(P, w) & \text { if } A(P, w)<0
\end{array}\right.
$$

Thus, krill grow in size when the assimilation net production is positive and shrink in size for small resource levels ${ }^{17}$.

The number of eggs produced by a female of the reproductive size and age equals

$$
\mu(P, a, w)= \begin{cases}(1-K(w)) \frac{\varepsilon_{\mathrm{ovary}} A(P, w)}{w_{\mathrm{egg}}}, & \text { if } A(P, w) \geq 0, w>w_{\mathrm{repr}}, a \geq a_{\mathrm{repr}} \\ 0, & \text { otherwise }\end{cases}
$$

where $\varepsilon_{\text {ovary }}$ is the relative weight of eggs in ovary tissue to the total dry weight of ovary tissue. As $A(P, w)$ depends on the food level, reproduction is possible only when food level is sufficient to cover the maintenance rate ${ }^{36}$. Consequently, the combination of grazing impact and seasonal variation in plankton production preclude reproduction in winter.

For the function $K(w)$, we use the logistic function ${ }^{37}$

$$
K(w)=\frac{1}{1+\mathrm{e}^{k_{\text {repr }}\left(L(w)-L_{\text {repr }}\right)}}
$$

where the parameter $L_{\text {repr }}$ defines the length at which $50 \%$ of krill stock attains maturity and $k_{\text {repr }}$ characterizes the steepness of the decrease of $K(L)$ with increasing $L$. For simplicity, we assume the same splitting function $K(w)$ for male and female krill.

Ingestion rates. Laboratory experiments show that the ingestion rate is likely to follow a sigmoidal Holling type III functional response ${ }^{38,39}$, but field data indicate that the individual growth rate instead follows Holling type II functional response ${ }^{33,40}$. Using different functional responses for growth and ingestion is problematic because it implies, for example, that at small resource concentration krill consumption rate is small, but the growth rate can be relatively high. To resolve this, we exploit the observation that the average grazing rate in a heterogeneous environment does not necessarily match the local grazing rate, measured in short-term experiments ${ }^{41}$, but should match on a global scale. Thus, to obtain the correct dependence of the growth rate on the resource availability, we assume that the weight-specific ingestion rate also follows a Holling type II function of the food concentration (which can be interpreted as an effective ingestion rate in a heterogeneous environment):

$$
I(P)=I_{\max } \frac{P}{P+H}
$$

where $I_{\max }$ is the maximal weight specific ingestion rate, $P$ is the resource concentration and $H$ is the half-saturation constant. For simplicity, we assume that $I_{\max }$ and $H$ do not depend on krill weight and age ${ }^{42}$ (see Supplementary Table 2 for parameters).

For krill larvae, which can feed on ice algae or phytoplankton, we assume an active switching strategy ${ }^{43,44}$ :

$$
I(P)=I_{\max } \frac{\sum \beta_{i} P_{i}}{H+\sum \beta_{i} P_{i}}
$$

where $\beta_{i}=P_{i} /\left(P_{\mathrm{Ph}}+P_{\mathrm{Ice}}\right)$ are the dynamical preferences for resource $i$ (with $i=\mathrm{Ph}$ or $i=$ Ice)

Our model neglects the dynamic feedback on phytoplankton and ice algae from other grazers, such Thysanoessa or salps, which also play an important role in WAP region ${ }^{45}$. However, krill is likely to be the main grazer in its habitat, because it typically dominates in the costal and shelf region, whereas salps dominate offshore, and krill and salp abundances negatively correlate ${ }^{12}$.

Background maintenance rate. According to equation (3), the change of weight of a starving adult equals $\mathrm{d} w / \mathrm{d} t=-T_{\mathrm{a}} w$, where $T_{\mathrm{a}}$ is the weight-specific background maintenance rate for adults. Therefore, we use the relation $w(t)=w(0) \mathrm{e}^{-T_{\mathrm{a}} t}$ and determine $T_{\mathrm{a}}$ to fit the results of starvation experiments ${ }^{17}$ (Supplementary Fig. 9d). Starving larvae have an oxygen consumption rate of approximately three times higher than starving adults ${ }^{16,17}$. Therefore, we assume for larvae $T_{1}=3 T_{\mathrm{a}}$ and a gradual decrease of the maintenance rate from $T_{1}$ to $T_{\mathrm{a}}$ with increasing krill size following the logistic function

$$
T(w)=\frac{T_{1}-T_{\mathrm{a}}}{1+\mathrm{e}^{k_{\mathrm{l}}\left(L(w)-L_{1}\right)}}+T_{\mathrm{a}}
$$

where $L_{1}$ is the characteristic size of larvae at which this transition should occur and $k_{1}$ is the steepness of this transition.

Daily growth rate. Experimental data, typically, provide the daily increase in body length ${ }^{33,46}, \mathrm{~d} L / \mathrm{d} t$, and for our model we need to determine the increase in body weight, $\mathrm{d} w / \mathrm{d} t$. To convert the units, we use the rule for the derivative of a composite function:

$$
\frac{\mathrm{d} w(L)}{\mathrm{d} t}=\frac{\mathrm{d} w(L)}{\mathrm{d} L} \frac{\mathrm{d} L}{\mathrm{~d} t}
$$

Substituting equations (1) and (2) into this expression and calculating all derivatives, we obtain the maximal daily growth rate in length:

$$
g_{\max }(L)=\frac{K(L)\left(\varepsilon I_{\max }-T\right) L}{\sigma_{1}+2 \sigma_{2} \ln L}
$$

Assimilation efficiency, $\varepsilon$, was chosen in such a way that the maximal daily growth rate (equation (5)) follows a hull above the experimental data points (the red line in Supplementary Fig. 9a). The other lines in this figure show the model predictions for the growth rate for different levels of food availability.

Fecundity as a function of body size can now be determined according to equation (4). Supplementary Fig. $9 \mathrm{~b}$ shows a good match between the experimenta data $^{47}$ and model predictions. Note, in ref. ${ }^{47}$ the authors calculated the number of mature oocytes, which can be more than 15,000 per female and can be released over two or three partial spawns. To estimate the daily fertility rate, we divided the number of oocytes by 45 days (one-half of the summer duration).

Krill mortality. The total mortality is a sum of background mortality $d_{\mathrm{b}}(w)$, which depends on krill weight, and starvation mortality, $d_{\mathrm{s}}(P, w)$, which depends on krill weight and on available resources, $d(P)=d_{\mathrm{b}}(w)+d_{\mathrm{s}}(P, w)$.

We assume that the background mortality decreases with stage, and krill has a finite life span of 5.9 years ${ }^{48}$. We use a fractional number for the life span to avoid a resonance between annual cycle in the model and life span of krill.

A previous study ${ }^{48}$ found that background mortality rate per year ranges from 0.52, during the maturation period, to 1.1, during the first year. We assume that mortality changes stepwise from $1 \mathrm{yr}^{-1}$ for juveniles to $0.5 \mathrm{yr}^{-1}$ for adults. From the experimental data, the background mortality can be found as, $m=(1 / t) \ln \theta$, where $\theta$ is the percentage of the population surviving after time $t$. In the experiments in ref. ${ }^{15}$, after 60 days approximately $20 \%$ of the population survived, which corresponds to $m=7.3 \mathrm{yr}^{-1}$. However, these experiments included only the first feeding stages (Calyptopis 1 to 3 ), and the authors mentioned that at the end of the period the population stabilized, so that the mortality rate decreased. The highest field estimation of mortality $2.31 \mathrm{yr}^{-1}$ was found in ref. ${ }^{49}$ for one-year-old krill. To keep the background mortality between these two extremes, we used the value of $5 \mathrm{yr}^{-1}$ for larvae.

The data on starvation mortality are even more scarce; in particular, no data are available on the dependence of starvation mortality on krill size and food availability. Thus, we parametrize the model to match the available data and use some additional assumptions to extend the dependences in the range, where no data are available. Furthermore, as our model assumes an exponential mortality rate, we can only specify a proportion $(<100 \%)$ of the population that dies during a period of time, whereas in starvation experiments typically the entire population dies after some period. In particular, it was found that the first feeding stages (Calyptopys 1) die during 10-14 days when starving ${ }^{15,16}$. To match this result, we assume that during 14 days approximately $80 \%$ of the population dies, which corresponds to the maximal starvation mortality rate, $d_{\mathrm{sl}}=40 \mathrm{yr}^{-1}$.

The maximal starvation mortality decreases with krill size, because adults can survive long periods of starvation. We assume that it decreases in the same way as the krill maintenance rate:

$$
d_{\mathrm{s}, \max }(w)=\frac{d_{\mathrm{sl}}}{1+\mathrm{e}^{k_{\mathrm{l}}\left(L(w)-L_{\mathrm{l}}\right)}}
$$

Finally, if assimilation is positive but not sufficient to cover the individual maintenance costs, we assume that the mortality rate follows a linear dependence on the relative difference between lack of resources for maintenance with respect to the maintenance rate (Supplementary Fig. 9c):

$$
d_{\mathrm{s}}(P, w)=\left\{\begin{aligned}
d_{\mathrm{s}, \max }(w)\left(\frac{T-\varepsilon I(P)}{T}\right), & \text { if } \varepsilon I(P)<T \\
0, & \text { if } \varepsilon I(P) \geq T
\end{aligned}\right.
$$


Metabolic rate. We assume that the relative metabolic rate of adults changes with season between $f_{\min }$ and 1 . To model this periodic dependence we use a modified von Mises distribution function:

$$
f_{\text {Met }}(t)=f_{\min }+\left(1-f_{\min }\right) \exp \left\{\frac{\cos \left[2 \pi\left(t-t_{\mathrm{Met}}\right)\right]-1}{\left(\pi T_{\mathrm{Met}}\right)^{2}}\right\}
$$

where $t_{\text {Met }}$ is the summer midpoint where $f_{\text {Met }}$ reaches a maximum, $T_{\text {Met }}$ is the duration of the active period and time is measured in years. A decrease of metabolic rate causes a proportional decrease of the maximal ingestion rate, which during winter reaches only $20 \%$ of the summer levels ${ }^{39}$. In the model, the period of high metabolic rates approximately matches the period of maximal phytoplankton concentrations.

Phytoplankton and ice algae. A previous study ${ }^{50}$ noted that net growth rate of phytoplankton differs substantially between the ocean and laboratory experiments ( 0.06 per day in the ocean versus 1 per day in laboratory experiments). Furthermore, the phytoplankton growth rate changes abruptly from positive during summer to negative during winter. Therefore, we model the growth rate by a stepwise function with a maximum in summer. To define it mathematically, we denote $T_{\mathrm{ph}}$ the duration of the period of phytoplankton growth and $t_{\mathrm{ph}}$ the midpoint of this period (both measured as a fraction of a year). Then the growth is positive if the difference between the current moment of time and the closest midpoint is less than $T_{\mathrm{Ph}} / 2$. Mathematically it can be, for instance, formulated as:

$$
g_{\mathrm{Ph}}(t)=\left\{\begin{array}{cc}
g_{\mathrm{Ph}, \max } & \text { if }\left[t-\left(t_{\mathrm{Ph}}+T_{\mathrm{Ph}} / 2\right)\right] \bmod 1>1-T_{\mathrm{Ph}} \\
0 & \text { otherwise }
\end{array}\right.
$$

Thus, during the period of positive growth (spring and summer), the net growth rate equals $g_{\mathrm{Ph}, \max }-l_{\mathrm{ph}}$, and during autumn and winter the net growth rate equals $-l_{\mathrm{ph}}$ (Supplementary Fig. 7b, black line). We choose $g_{\mathrm{Ph}, \max }, t_{\mathrm{ph}}, T_{\mathrm{Ph}}, l_{\mathrm{ph}}$ and $K_{\mathrm{Ph}}$ to match the experimental data obtained at the coastal station of the Palmer LTER (Supplementary Fig. 7b).

For ice algae, we assume that the growth rate is a periodic function of time:

$$
g_{\text {Ice }}(t)=g_{\text {Ice, } \max } \exp \left\{\frac{\cos \left[2 \pi\left(t-t_{\text {Ice }}\right)\right]-1}{\left(\pi T_{\text {Ice }}\right)^{2}}\right\}
$$

This reaches a maximum of $g_{\text {Ice } \max }$ at the midpoint of the ice algae production, $t_{\text {Ice, }}$ and $T_{\text {Ice }}$ characterizes the duration of ice algae growth (see Supplementary Fig. $7 \mathrm{~b}$ for an exemplary model outcome).

Note that our model shows a strong effect of krill on pelagic phytoplankton but not on ice algae. This is caused by the model parametrization, which assumes a relatively smaller net growth rate of the pelagic phytoplankton in comparison with ice algae.

Data and computer code availability. The data that support the findings of this study are available from the Palmer LTER data archive (http://pal.lternet.edu/data). The $\mathrm{C}++$ computer code of the ontogenetic model of krill population dynamics is available as an electronic Supplementary Material for the paper; the latest version of the project is available from the corresponding author on request or at http:// www.staff.uni-oldenburg.de/alexey.ryabov/download.html.

Received 2 July 2016; accepted 3 May 2017; published 5 June 2017

\section{References}

1. Hewitt, R. P., Demer, D. A. \& Emery, J. H. An 8-year cycle in krill biomass density inferred from acoustic surveys conducted in the vicinity of the South Shetland Islands during the austral summers of 1991-1992 through 2001-2002. Aquat. Living Resour. 16, 205-213 (2003).

2. Quetin, L. B. \& Ross, R. M. Episodic recruitment in Antarctic krill Euphausia superba in the Palmer LTER study region. Mar. Ecol. Prog. Ser. 259, 185-200 (2003).

3. Fielding, S. et al. Interannual variability in Antarctic krill (Euphausia superba) density at South Georgia, Southern Ocean: 1997-2013. ICES J. Mar. Sci. 71, 2578-2588 (2014).

4. Ross, R. M. et al. Trends, cycles, interannual variability for three pelagic species west of the Antarctic Peninsula 1993-2008. Mar. Ecol. Prog. Ser. 515, 11-32 (2014).

5. Atkinson, A. et al. Oceanic circumpolar habitats of Antarctic krill. Mar. Ecol. Prog. Ser. 362, 1-23 (2008).

6. Atkinson, A., Siegel, V., Pakhomov, E. \& Rothery, P. Long-term decline in krill stock and increase in salps within the Southern Ocean. Nature 432, 100-103 (2004).

7. Knox, G. A. Biology of the Southern Ocean 2nd edn (CRC, 2006),

8. Atkinson, A., Siegel, V., Pakhomov, E. A., Jessopp, M. J. \& Loeb, V. A re-appraisal of the total biomass and annual production of Antarctic krill. Deep-Sea Res. I 56, 727-740 (2009).
9. Saba, G. K. et al. Winter and spring controls on the summer food web of the coastal West Antarctic Peninsula. Nat. Commun. 5, 4318 (2014).

10. Ducklow, H. W. et al. Marine pelagic ecosystems: the West Antarctic Peninsula. Phil. Trans. R. Soc. B 362, 67-94 (2007).

11. Loeb, V. in The Impact of Environmental Variability on Ecological Systems (eds Vasseur, D. A. \& McCann, K. S.) 197-225 (Springer, 2007).

12. Steinberg, D. K. et al. Long-term (1993-2013) changes in macrozooplankton off the Western Antarctic Peninsula. Deep-Sea Res. I 101, 54-70 (2015).

13. Quetin, L. B., Ross, R. M., Fritsen, C. H. \& Vernet, M. Ecological responses of Antarctic krill to environmental variability: can we predict the future? Antarct. Sci. 19, 253-266 (2007).

14. Nicol, S. Krill, currents, and sea ice: Euphausia superba and its changing environment. BioScience 56, 111-120 (2006).

15. Ross, R. M., Quetin, L. B. \& Kirsch, E. Effect of temperature on developmental times and survival of early larval stages of Euphausia superba Dana. J. Exp. Mar. Biol. Ecol. 121, 55-71 (1988).

16. Meyer, B. \& Oettl, B. Effects of short-term starvation on composition metabolism of larval Antarctic krill, Euphausia superba. Mar. Ecol. Prog. Ser. 292, 263-270 (2005).

17. Ikeda, T. \& Dixon, P. Body shrinkage as a possible over-wintering mechanism of the Antarctic krill, Euphausia superba Dana. J. Exp. Mar. Biol. Ecol. 62, 143-151 (1982).

18. Ross, R. M., Quetin, L. B. \& Haberman, K. L. Interannual and seasonal variability in short-term grazing impact of Euphausia superba in nearshore and offshore waters west of the Antarctic Peninsula. J. Mar. Syst. 17, 261-273 (1998).

19. Moran, P. A. P. The statistical analysis of the Canadian lynx cycle. Aust. J. Zool. 1, 291-298 (1953).

20. Massie, T. M., Weithoff, G., Kuckländer, N., Gaedke, U. \& Blasius, B. Enhanced Moran effect by spatial variation in environmental autocorrelation. Nat. Commun. 6, 5993 (2015).

21. Smith, L. V. et al. Preliminary investigation into the stimulation of phytoplankton photophysiology and growth by whale faeces. J. Exp. Mar. Biol. Ecol. 446, 1-9 (2013).

22. Murphy, E. J. et al. Spatial and temporal operation of the Scotia Sea ecosystem: a review of large-scale links in a krill centred food web. Phil. Trans. R. Soc. B 362, 113-148 (2007).

23. Reid, K. \& Croxall, J. P. Environmental response of upper trophic-level predators reveals a system change in an Antarctic marine ecosystem. Proc. $R$. Soc. Lond. B 268, 377-384 (2001).

24. Abrams, P. A., Brassil, C. E. \& Holt, R. D. Dynamics and responses to mortality rates of competing predators undergoing predator-prey cycles. Theor. Popul. Biol. 64, 163-176 (2003).

25. Fraser, W. R. \& Hofmann, E. E. A predator's perspective on causal links between climate change, physical forcing and ecosystem. Mar. Ecol. Prog. Ser. 265, 1-15 (2003).

26. Pennington, M. Efficient estimators of abundance, for fish and plankton surveys. Biometrics 39, 281-286 (1983)

27. Atkinson, A. et al. Fitting Euphausia superba into Southern Ocean food-web models: a review of data sources and their limitations. CCAMLR Sci. 19, 219-245 (2012).

28. Pakhomov, E. A. Demographic studies of Antarctic krill Euphausia superba in the Cooperation and Cosmonaut seas(Indian sector of the Southern Ocean). Mar. Ecol. Prog. Ser. 119, 45-61 (1995).

29. Meyer, B. The overwintering of Antarctic krill, Euphausia superba, from an ecophysiological perspective. Polar Biol. 35, 15-37 (2012).

30. de Roos, A. M \& Persson, L. Population and Community Ecology of Ontogenetic Development (Princeton Univ. Press, 2013).

31. De Roos, A. M., Diekmann, O. \& Metz, J. A. J. Studying the dynamics of structured population models: a versatile technique and its application to Daphnia. Am. Nat. 139, 123-147 (1992).

32. Quetin, L. B. \& Ross, R. M. Depth distribution of developing Euphausia superba embryos, predicted from sinking rates. Mar. Biol. 79, 47-53 (1984).

33. Atkinson, A. et al. Natural growth rates in Antarctic krill (Euphausia superba): II. Predictive models based on food, temperature, body length, sex, and maturity stage. Limnol. Oceanogr. 51, 973-987 (2006).

34. Meyer, B. et al. Physiology, growth and development of larval krill Euphausia superba in autumn and winter in the Lazarev Sea, Antarctica. Limnol. Oceanogr. 54, 1595-1614 (2009).

35. Lowe, A. T., Ross, R. M., Quetin, L. B., Vernet, M. \& Fritsen, C. H. Simulating larval Antarctic krill growth and condition factor during fall and winter in response to environmental variability. Mar. Ecol. Prog. Ser. 452, $27-43(2012)$

36. Harrington, S. A. \& Ikeda, T. Laboratory observations on spawning, brood size and egg hatchability of the Antarctic krill Euphausia superba from Prydz Bay, Antarctica. Mar. Biol. 92, 231-235 (1986).

37. Siegel, V. \& Loeb, V. Length and age at maturity of Antarctic krill. Antarct. Sci. 6, 479-482 (1994). 
38. Atkinson, A., Meyer, B., Bathmann, U., Hagen, W. \& Schmidt, K. Feeding and energy budget of Antarctic krill Euphausia superba at the onset of winter: II. Juveniles and adults. Limnol. Oceanogr. 47, 953-966 (2002).

39. Meyer, B. et al. Seasonal variation in body composition, metabolic activity, feeding, and growth of adult krill Euphausia superba in the Lazarev Sea. Mar. Ecol. Prog. Ser. 398, 1-18 (2010).

40. Ross, R. M., Quetin, L. B., Baker, K. S., Vernet, M. \& Smith, R. C. Growth limitation in young Euphausia superba under field conditions. Limnol. Oceanogr. 45, 31-43 (2000).

41. Englund, G. \& Leonardsson, K. Scaling up the functional response for spatially heterogeneous systems. Ecol. Lett. 11, 440-449 (2008).

42. Hofmann, E. E. \& Lascara, C. M. Modeling the growth dynamics of Antarctic krill Euphausia superba. Mar. Ecol. Prog. Ser. 194, 219-231 (2000).

43. Gentleman, W., Leising, A., Frost, B., Strom, S. \& Murray, J. Functional responses for zooplankton feeding on multiple resources: a review of assumptions and biological dynamics. Deep-Sea Res. II. 50, 2847-2876 (2003).

44. Ryabov, A. B., Morozov, A. \& Blasius, B. Imperfect prey selectivity of predators promotes biodiversity and irregularity in food webs. Ecol. Lett. 18, 1262-1269 (2015).

45. Sailley, S. F. et al. Carbon fluxes and pelagic ecosystem dynamics near two Western Antarctic Peninsula Adélie penguin colonies: an inverse model approach. Mar. Ecol. Prog. Ser. 492, 253-272 (2013).

46. Kawaguchi, S., Candy, S. G., King, R., Naganobu, M. \& Nicol, S. Modelling growth of Antarctic krill. I. Growth trends with sex, length, season, and region. Mar. Ecol. Prog. Ser. 306, 1-15 (2006).

47. Tarling, G. A. et al. Recruitment of Antarctic krill Euphausia superba in the South Georgia region: adult fecundity and the fate of larvae. Mar. Ecol. Prog. Ser. 331, 161-179 (2007).

48. Pakhomov, E. A. Natural age-dependent mortality rates of Antarctic krill Euphausia superba Dana in the Indian sector of the Southern Ocean. Polar Biol. 15, 69-71 (1995).

49. Brinton, E. \& Townsend, A. W. Regional relationships between development and growth in larvae of Antarctic krill, Euphausia superba, from field samples. J. Crustacean Biol. 4, 224-246 (1984).

50. Behrenfeld, M. J. Abandoning Sverdrup's critical depth hypothesis on phytoplankton blooms. Ecology 91, 977-989 (2010).

\section{Acknowledgements}

We thank A. Atkinson, L. B. Quetin and R. M. Ross for useful comments on the manuscript; A.B.R. acknowledges support from the Helmholtz Virtual Institute PolarTime (VH-VI-500); A.M.d.R. is supported by funding from the European Research Council under the European Unions Seventh Framework Programme (FP/2007-2013)/ ERC Grant Agreement No. 322814. This work contributes to the PACES (Polar Regions and Coasts in a changing Earth System) program (Topic 1, WP 5) of the Alfred Wegener Institute Helmholtz Centre for Polar and Marine Research. Data on krill abundance and biomass were retrieved from the Palmer LTER data archive (http://pal.lternet.edu/ data) and data on size distributions were provided by L. B. Quetin and R. M. Ross. The Palmer LTER research was supported by the National Science Foundation, Office of Polar Programs, under Award Nos. OPP-9011927, OPP-9632763, OPP-0217282, ANT-1010688 and PLR-1440435, the Regents of the University of California, the University of California at Santa Barbara, and the Marine Science Institute, UCSB.

\section{Author contributions}

All authors designed the research; A.B.R., A.M.d.R., B.B. developed the model; A.B.R., S.K., B.M. parametrized the model, A.B.R. performed computer experiments and data analysis; A.B.R. and B.B. with contributions from other authors wrote the paper.

\section{Additional information}

Supplementary information is available for this paper.

Reprints and permissions information is available at www.nature.com/reprints. Correspondence and requests for materials should be addressed to A.B.R.

How to cite this article: Ryabov, A. B., de Roos, A. M., Meyer, B., Kawaguchi, S. \& Blasius, B. Competition-induced starvation drives large-scale population cycles in Antarctic krill. Nat. Ecol. Evol. 1, 0177 (2017).

Publisher's note: Springer Nature remains neutral with regard to jurisdictional claims in published maps and institutional affiliations.

\section{Competing interests}

The authors declare no competing financial interests. 